\title{
CARACTERIZAÇÃO PETROGRÁFICA E METAMÓRFICA DOS GRANULITOS DO ARQUEANO/PROTEROZÓICO INFERIOR DA REGIÃO DE ITABUNA - BAHIA
}

\author{
JOÃO B. A. ARCANJO*, JOHILDO S. F. BARBOSA* e JOSÉ E. OLIVEIRA**
}

\begin{abstract}
PETROGRAPHIC AND METAMORPHIC CHARACTERIZATION OF THE ARCHEAN/ LATE-PROTEROZOIC GRANULITES OF THE REGION OF ITABUNA-B AMI A. The Archean/Lower Proterozoic high-grade rocks ofthe Itabunaregion in southern Bahia were separated into five assemblages. The first one was named Illéus Complex, being formedby intercalationsofbasic granulites with hornblende and felsic granulites with plagioclase. The second, São José Complex, is composed of intermediate to basic granulites with intercalations of garnet bearing basic granulites. The third, IbicarairBueTarema Complex is formed essentially of intermediate granulites and a fourth assemblage that comprises the Água Sumida (metamonzonites), Rio Paraíso (meta-syenites)and São Geraldo granitoids (this latter one of granitic composition). All the rocks ofthe former four assemblages are ofthe granulite facies of metamorphisrn. The fifth and last assemblage was named Rio Japu, being formed mostly of biotite and hornblende gneisses re-adjusted to the amphibolite facies conditions. Besides the amphibolite and granulite progressive facies the paragenetic and textural studies ofthe metamorphic reactions and mineral chemistry allowed to recognize the granulite, amphibolite and greenschist regressive facies in the area. The temperatures and pressure values for the maximum metamorphism were estimated in $6 \mathrm{kbar}$ and $850^{\circ} \mathrm{C}$. The geotectonic model forthe area is in agreement with the one interpreted for a northern area. In that place is taken into account the existence of a subduction zone closer to the Atlantic coastal zone and, an arc or a series of island arcs as one moves inboard the continent.
\end{abstract}

Keywords: Granulites, petrology, metamorphism, termobarometry.

\begin{abstract}
RESUMO As rochas arqueanas/proterozóicas inferiores de alto grau da região de Itabuna, no sul da Bahia, foram separadas em cinco grupos. O primeiro foi denominado de Complexo Ilhéus, sendo formado de intercalates de granul itos máficos com homblenda com granulitos félsicos plagioclásicos. O segundo, de Complexo São José, composto de granulitos intermediários abásicos, com intercalações de granul itos básicos com granada. O terceiro, de Complexo Ibicaraí-Buerarema, constituído essencialmente de granulitos intermediários; e o quarto grupo, no qual estão encerrados os granitóides Água Sumida (metamonzonitos), Rio Paraíso (meíassienitos) e São Geraldo, este último de composição granítica. Todas as rochas dos quatro primeiros grupos são da fácies granul ito. O quinto e último grupo foi denominado de Complexo Rio Japu, sendo constituído notadamente de biotita e hornblenda gnaisses reequilibrados na fácies anftbolito. Além das fácies granulito e anflbolito, progressivas, os estudos paragenéticos e texturais das reações metamórficas e de química mineral permitiram identificar as fácies granulito, anflbolito e xisto-verde regressivas na região. Os valores de temperaturae pressão paraopico do metamorfismo foram estimados em $6 \mathrm{kbare} 850^{\circ} \mathrm{C}$. $\mathrm{O}$ modelo geotectônico da área coaduna-se com aquele interpretado mais ao norte. Naquelaregião é consideradaaexistênciade zona de subducção, mais próxima àzona costeira atlânticae, um arco, ou conjunto de arcos de ilhas, mais p ara o interior.
\end{abstract}

Palavras-chaves: Granulitos, petrologia,metamorfismo, termobarometria.

INTRODUÇÃO Os elementos expostos neste trabalho foram obtidos durante o mapeamento geológico da Folha Itabuna, dentro do Programa de Levantamentos Geológicos Básicos, executado pelo Convênio DNPM/CPRM (Arcanjo 1991, no prelo). A área estudada situa-se na parte litorânea sul do Estado da Bahia (Fig. I), no denominado Cinturão Móvel Costeiro Atlântico (Mascarenhas 1979), cujas rochas, essencialmente granulíticas, estendem-se numa faixa contínua, desde a região do Baixo Rio Pardo, no sul do Estado, até o vale do Rio Curaçá, ao norte.

Essas rochas de alto grau de metamorfismo vêm sendo estudadas desde a década de 70 , destacando-se entre os principais trabalhos aqueles desenvolvidos por Sighinolfi (1970,1971), Cordani (1973), Seixas et al. (1975), Sighinolfi \& Sakai (1977), Cordani \& Iyer (1979), Neves et al.(1980), Sighinolfi et al. (1981), Costa \& Mascarenhas (1982), Lima et al. (1982), Oliveira \& Lima (1982), Oliveira et al. (1982), Miranda et al. (1982,1985), Ribeiro (1982), Iyer et al. (1984, 1987), Delhal \& Demaiffe (1985), Barbosa (1986, 1988, 1989, 1990, 1991), Barbosa \& Fonteilles (1986, no prelo), Wilson (1 987), Wilson et al. (1988), Sampaio \& Silva (1 988), Cruz (1989), os quais contribuíram com importantes informações sobre a geologia dessa faixa granulítica do Estado da
Bahia. Entretanto, foram os trabalhos realizados a partir de 1985, focalizando principalmente a petroquímica dessas rochas, que forneceram nova concepção de estudo para esses terrenos de alto grau metamórfico, inclusive com estabelecimento de parâmetros que permitiram, juntamente com a cartografia, individualizar domínios litológicos até então não reconhecidos.

Assim, na parte oriental da região granulítica do sul da Bahia, foi definido o Domínio da Costa Atlântica (Barbosa 1986), cujo grau de deformação e recristalização só raramente permite identificar a natureza original dos granulitos, se vulcânica ou plutônica, embora tenha sido possível, com os estudos petroquímicos, interpretar a filiação magmática de seus protólitos (Barbosa 1990). De leste para oeste, este Domínio é composto de (Barbosa 1991): l. granulitos máficos com granada (protólitos com idade $\mathrm{Sm} / \mathrm{Nd} \mathrm{de}+2,9 \mathrm{Ga}$, semelhantes a basaltos e/ou gabros toleíticos de arcos vulcânicos); 2. granulitos intermediários e félsicos (protólitos com idade $\mathrm{Sm} / \mathrm{Nd}$ de $+2,6 \mathrm{Ga}$, semelhantes a andesitos basálticos e/ou andesitos e/ou quartzo dioritos, dacitos e/ou tonalitosenderbitos e riolitos e/ou trondhjemitos, correspondentes a uma seqüência cálcio-alcalina do tipo arco de ilhas); e 3. granulitos máficos com antipertita (protólitos com idade Sm- 


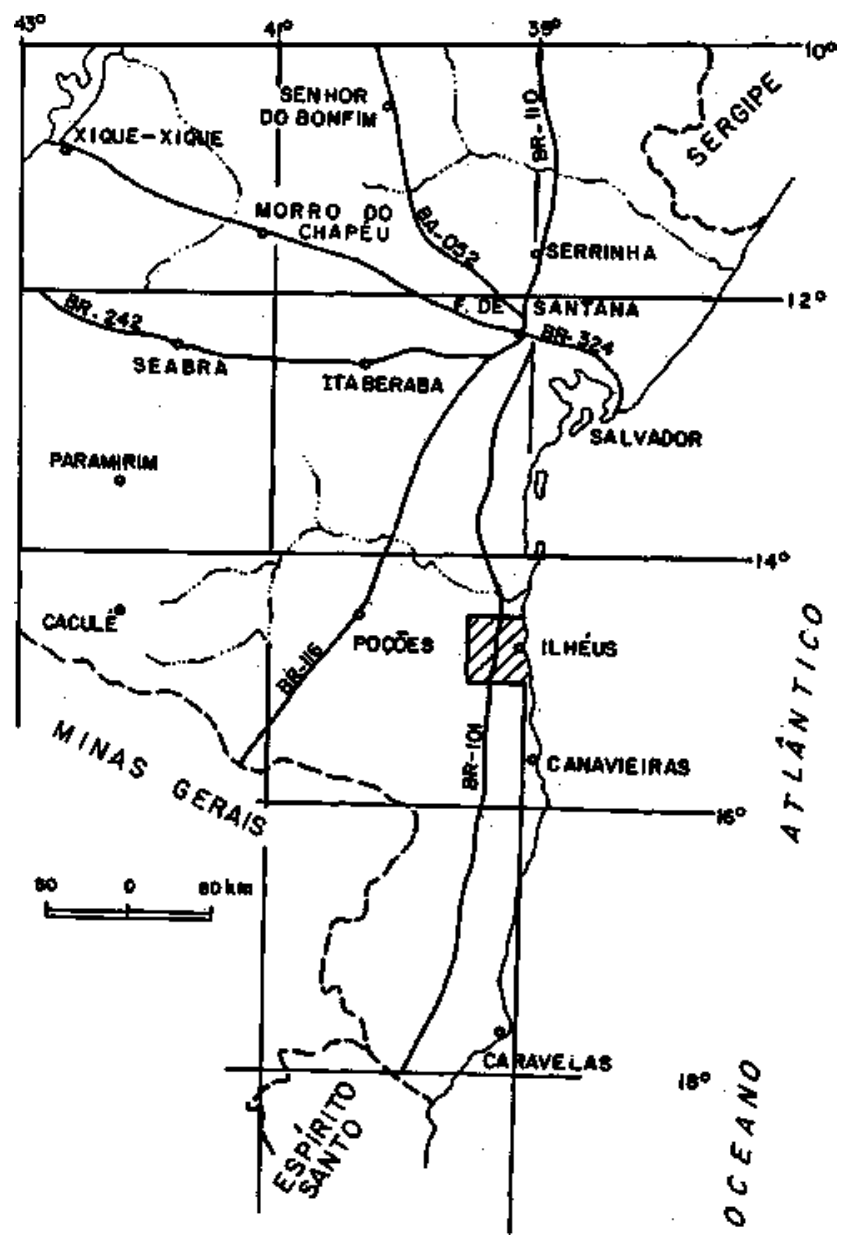

Figura 1 - Localização da área pesquisada, ao sul do Estado da Bahia

Figure 1 - Situation of the studied area relative to the South of Bahia State

$\mathrm{Nd}$ de $+2,4 \mathrm{Ga}$, semelhantes aos andesitos basálticos e/ou monzonitos-mangeritos e andesitos e/ou quartzo-monzonitos, provavelmente derivados de magma shoshonítico-alcalino, encontrado em arcos de ilhas). Todas estas rochas granulíticas, vulcânicas e/ou plutônicas, mantêm disposição geográfica que permite interpretar a existência de provável arco de ilha, de idade arqueana/proterozóica inferior, profundamente erodido. Este arco de ilha pode ter sido produto da fusão com formação de magma toleítico, cálcio-alcalino e shoshonítico de suposta placa oceânica, com vergência para oeste. Segundo Barbosa (1990), este segmento crustal de arco de ilhas teria sido obductado sobre um protocontinente (Complexo Jequié), situado a oeste da região em questão, fazendo sobrepor, também sobre este último, rochas de provável bacia pós-arco, situada entre o arco e o continente. As fases de deformação, além do metamorfísmo de alto grau identificados na região, foram possivelmente produzidos como conseqüência desses processos de colisão, os quais promoveram duplicação da crosta nesta parte da Bahia.

Sobre as deformações tectônicas, quatro fases foram identificadas na região: a primeira-(D1) é representada por um bandamento gnáissico original (S1); a segunda (D2), por uma foliação de plano axial de baixo ângulo de mergulho (S2), associada a dobras recumbentes, isoclinais deitadas, freqüentemente transpostas (Barbosa 1986); a terceira (D3) é evidenciada através de foliação verticalizada (S3), que trunca e às vezes transpõe as foliações precedentes, constituindo plano axial de dobras apertadas, simétricas e assimétricas (Barbosa 1986); finalmente, a quarta e última

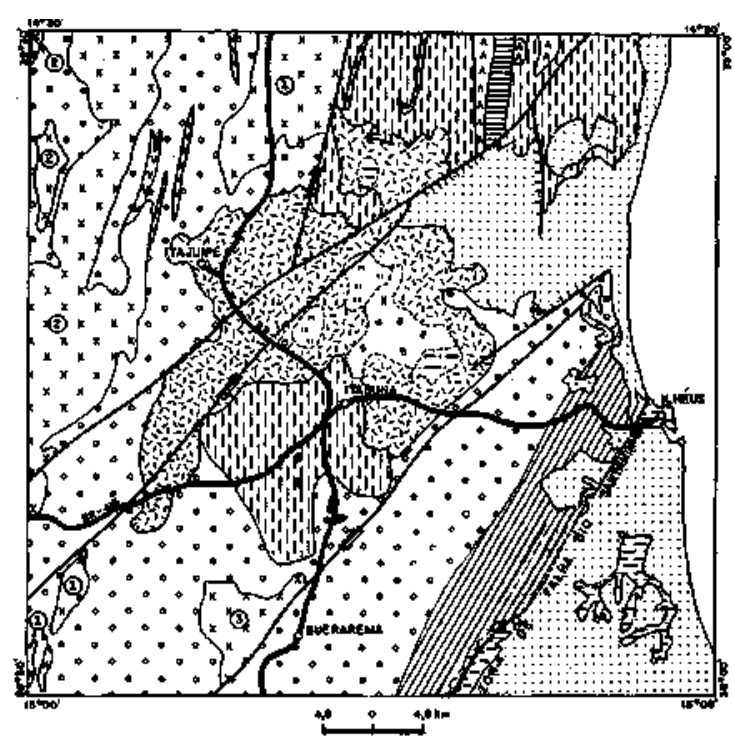

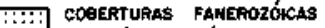

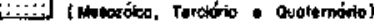

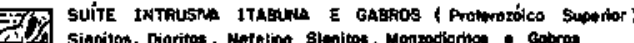

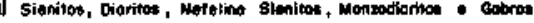

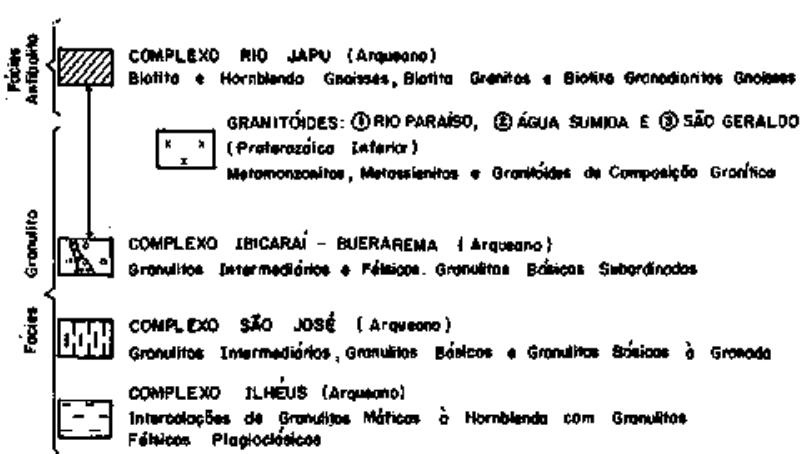

Figura 2 - Mapa geológico simplificado da área pesquisada Figure 2 - Simplified geological map of the studied area

(D4), pouco penetrativa e raramente observada, marcando foliação espaçada (clivagem de fratura) de direção N70E (S4). A terceira fase é a mais importante, pois controla os principais trends regionais (N10-20E), sendo acompanhada por cisalhamento transcorrente, marcado por lineação de estiramento mineral com mergulho de 10-20S (Barbosa 1986). Este trabalho refere-se somente à geologia das rochas de alto grau, de idade arqueana e/ou proterozóica inferior, que ocorrem na região. São excluídos, portanto, os dados referentes aos diques de diabásio e basalto de preenchimento de fraturas do Proterozóico Superior, aos corpos magmáticos anorogênicos, também do Proterozóico Superior (Suíte Intrusiva Itabuna de Lima et al. 1981), e às coberturas fanerozóicas do Mesozóico, Terciário e Quaternário (Fig. 2).

PETROGRAFIA - UNIDADES GEOLÓGICAS Estudos petrográficos acoplados aos estudos petroquímicos e aos mapeamentos geológico e geofísico permitiram separar as rochas metamórficas arqueanas/proterozóicas inferiores de alto grau da região de Itabuna em cinco grupos distintos, com características próprias, a saber: 1. Complexo Ilhéus; 2. Complexo São José; 3. Complexo Ibicaraí-Buerarema; 4. Granitóides Rio Paraíso, Água Sumida e São Geraldo; 5. Complexo Rio Japu. Essas unidades em geral estão limitados por descontinuidades estruturais profundas, representadas 

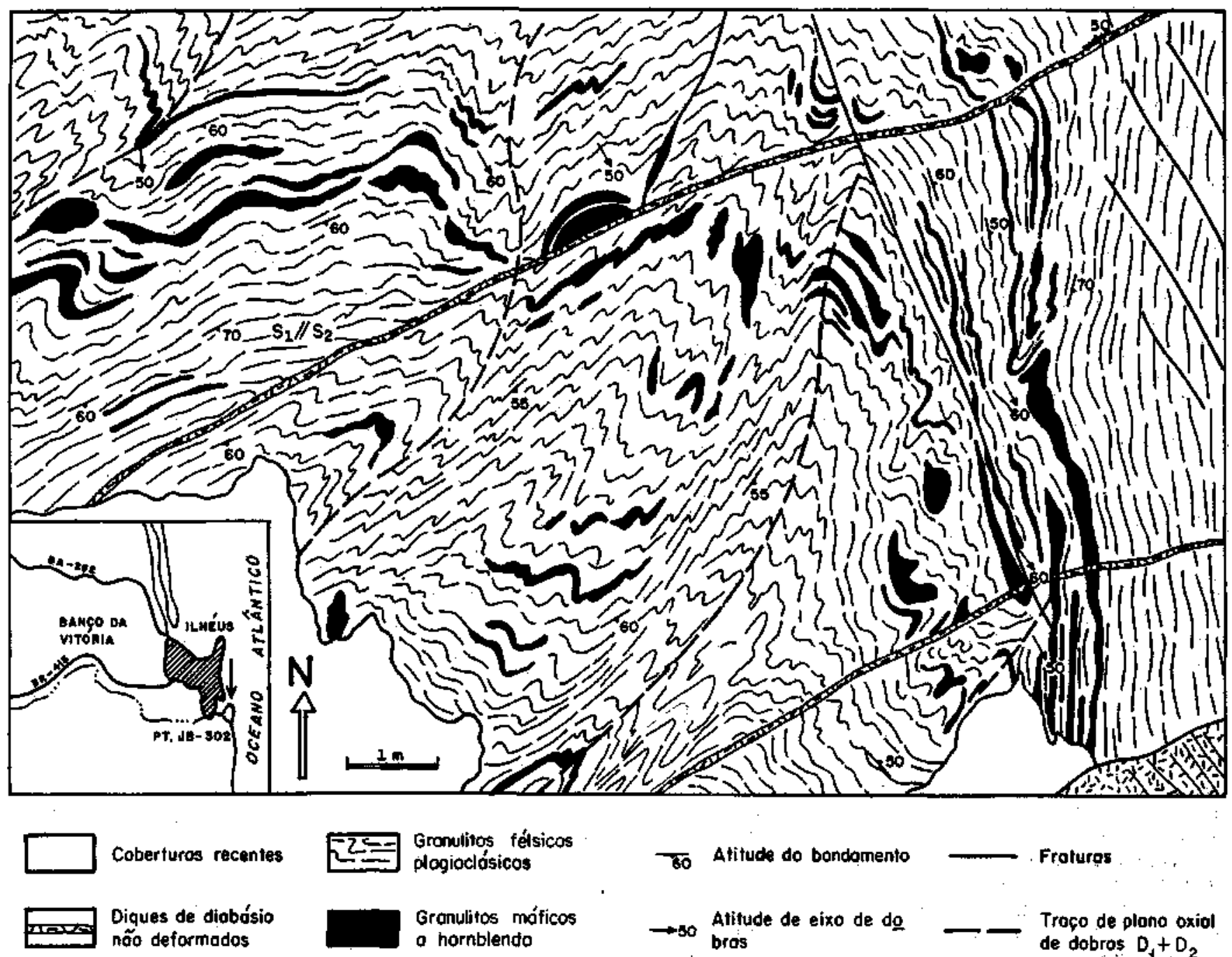

Froluras

Figura 3 - Mapa de detalhe de afloramento do Complexo Ilhéus situado na cidade do mesmo nome. Observar a persistência das bandas de granulitos máficos que, apesar das deformações, podem ser reconstituídas geometricamente. A leste deste afloramento, as foliações provenientes de D1 e D2 são reortentadas por D3

Figure 3 - Detailed map ofthe outcrop ofthe Ilhéus Complex situated inside Illhéus city. Observe the persistency ofthe mafic granulite bands, which can be reconstituted geometrically, in spite ofthe deformations. East of this outcrop the foliations caused by D1 and D2 are re-oriented by D3

por zonas de cisalhamento, associadas às deformações tectônicas dúcteis referidas anteriormente.

Complexo Ilhéus Este complexo encontra-se restrito à parte sudeste da região e mostra raros afloramentos, já que é praticamente todo recoberto por sedimentos fanerozóicos. Seu limite oeste é realizado através da falha/zona de cisalhamento Rio Santaninha (Fig, 2), sobrepondo-o aos gnaisses da fácies anfibolito, pertencentes ao Complexo Rio Japu, descrito mais adiante.

Com os melhores afloramentos situados ao longo do litoral entre as cidades de Ilhéus e Olivença (Figs. 2 e 3), as rochas deste complexo são granulitos fortemente bandados, que correspondem provavelmente a associação de natureza dominantemente vulcânica e/ou vulcanoclástica. Predominam bandas milimétricas a métricas de granulitos félsicos, plagioclásicos, de composição dacítica e termos andesíticos subordinados, com intercalações de bandas, tambérrj de espessura milimétrica a métrica, de granulitos máficos com hornblenda de composição basáltica/andesítica. Níveis félsicos com textura grossa, possivelmente plutônica e de composição tonalítica (sheets intrusivos?), também associam-se a esta seqüência. Ainda está incluído neste Complexo, um corpo de "hiperstênio" tonalito-gnaisse, plutônico, possivelmente anatético, sem relações visíveis com a associação bandada félsica-máfica. Vale registrar que as bandas máficas, apesar de freqüentemente "boudinadas" pelas deformações superimpostas, podem ser reconstituídas geometricamente, havendo persistência na continuidade desses níveis (Fig. 3). $\mathrm{Na}$ mesma figura, que exemplifica um dos mais representativos afloramentos do Complexo Ilhéus, verifica-se, na parte mais oriental, que a deformação (D3) transpôs e reorientou, na direção regional, os planos de foliação (SI e S2) das deformações anteriores (D1 e D2).

Macroscopicamente, as bandas félsicas apresentam coloração cinza e granulação, em geral, de fina a média, localmente grossa. Microscopicamente, estes granulitos félsicos têm mosaico composto por quartzo estirado $(60 \%)$ e plagioclásio (36\%) (An 30-50), formando níveis milimétricos. Ortopiroxênio é raro, mas quando ocorre está associado com hornblenda, em geral retrógrada, perfazendo os $4 \%$,

As bandas máficas apresentam cor cinza-escuro e textura de fina a média. Ao microscópio, exibem textura granoblástica, com bandamento gnáissico proveniente da alternância de faixas ricas em piroxênios, hornblendas e opacos e outras ricas em andesina e quartzo. Localmente, estes níveis máficos 
são compostos de labradorita (51\%), clinopiroxênio (17\%), granada $(13 \%)$, quartzo $(10 \%)$ e escapolita $(8 \%)$, sem ortopiroxênio.

Dois fatos resultantes dos estudos petrográficos dessas rochas, e que conduzem a que sejam consideradas como formadas na parte superficial da crosta, merecem destaque. $\mathrm{O}$ primeiro é sobre a ocorrência de zircão possivelmente detrítico alinhado, em nível félsico, de espessura centimétrica, contendo $60 \%$ de quartzo, e embutido em banda de granulito máfico. $\mathrm{O}$ segundo refere-se à constatação de nível máfico enriquecido em sódio, por causa da presença de egirina-augita e escapolita. Este nível pode representar: 1. sedimentos margosos com certa quantidade de material sal ino (evaporito?); 2. material metassomatizado em sódio antes e/ou durante o metamorfismo; 3. rocha basáltica espilitizada; ou ainda; 4. rocha piroclástica alcaüna. Sobre a petroquímica, em diagramas que discriminaram rochas ígneas de sedimentares (exemplo, Garreis \& Mackenzie 1971), algumas das amostras do Complexo Ilhéus situam-se na interface ígnea/sedimentar ou mesmo no domínio sedimentar, corroborando os dados petrográficos e de campo, que apontam origem supracrustal para essas rochas.

Complexo São José Ocupa as partes nordeste e centro da área em foco (Fig. 2), sendo composto de granulitos intermediários, granulitos básicos e granulitos básicos com granada - estes últimos representam segmento importante do Complexo.

Granulitos intermediários São rochas de coloração cinzaesverdeado, granulação em geral fina a média e com estrutura bandada, materializada na discreta presença de níveis mais félsicos intercalados com níveis mais intermediários. Em lâmina delgada, mostram textura ineqüigranular a eqüigranular, com os contornos entre os grãos mais ou menos retos e com estrutura gnáissica, definida pela alternância de bandas onde ocorrem alguns minerais máficos (piroxênios + hornblenda) e bandas onde estes são inexistentes; plagioclásio e quartzo são os minerais predominantes. A paragênese metamórfíca de alto grau é composta de plagioclásio $(70 \%)$ (An 30-50), quartzo (20\%) e ortopiroxênio (5\%), sendo o clinopiroxênio raro. Os minerais ferromagnesianos $(5 \%)$ estão, às vezes, transformados para associação de minerais neoformados, contendo hornblenda + biotita + quartzo + opacos.

Conforme assinalou Barbosa (1990), em função das fortes deformações tectônicas associadas e recristalizações na fácies granulito de alta temperatura, a estrutura original dessas rochas é difícil de ser distinguida. A mineralogia indica que elas foram ígneas, mas não há elementos macro ou microscópicos indiscutíveis que permitam classificá-las com segurança como tonalitos ou dacitos, antes da granulitização.

Granulitos básicos e granulitos básicos com granada Os granulitos básicos são encontrados sob a forma de corpos estirados, dispostos linearmente na direção N-S. Apresentam cor cinza-escuro a cor cinza-esverdeado, granulação de fina a média, por vezes grossa. Possuem textura blastomilonítica, às vezes poligonal, diferenciando-se dos granulitos intermediários anteriores pela maior quantidade de ortopiroxênio $(20 \%)$, clinopiroxênio $(25 \%)$, e proporção menor de plagioclásio (53\%) (An 45-50) e quartzo (2\%). Assim, como no caso dos granulitos intermediários, não é fácil distinguir a natureza original dessas rochas. Entretanto, neste caso, em espécimens de textura grossa, são verificadas, ao microscópio, relíquias de textura subofítica, denunciada por agrupamento de grãos de ortopiroxênio limitados por concentrações de plagioclásio, que, apesar dos processos de cominuição, guardam a mesma organização mineralógica-textural original. Texturas parecidas com aquelas de cumulus também se fazem presentes localmente, evidenciadas pela disposição dos cristais de piroxênio em relação ao plagioclásio, indicando que alguns cristais de piroxênio foram "depositados" sobre os plagioclásios. Em rochas semelhantes, situadas ao norte da área em foco, Barbosa (1991) identificou em pares de ortopiroxênio-clinopiroxênio temperaturas de cristalização superiores a $900^{\circ} \mathrm{C}$. Estas podem ser interpretadas como temperaturas plutônicas, parcialmente reequilibradas pelo metamorfismo granulítico (Barbosa 1986).

Os granulitos deste Complexo estão intensamente deformados, com foliação milonítica antiga, recristalizada, na qual são observados grãos de quartzo estirados no plano da foliação. $\mathrm{O}$ mesmo parece não acontecer com os sills básicos que intrudem este complexo, que, em primeira análise, apresentam trama menos deformada, sendo neles visível apenas a foliação S3, proveniente da terceira fase de deformação dúctil (D3).

Ao lado dessas rochas, são encontrados granulitos básicos com granada, de textura fina, aspecto homogêneo, cor cinzaescuro e suave bandamento, assinalado pela presença de grãos de granada arrumados em bandas que se alternam com outras, formadas ora de quartzo e feldspato, ora de minerais ferromagnesianos. Estas características mineralógicas e texturais fazem supor que poderiam ter sido metabasaltos reequilibrados na fácies granulito, atualmente mostrando textura granoblástica-poHgonal a porfiroblástica. A paragênese de alto grau é formada de plagioclásio (50\%) (An 40-50), ortopiroxênio $(15 \%)$, clinopiroxênio $(15 \%)$, granada $(10 \%)$ e quartzo $(2 \%)$. Hornblenda $(6 \%)$ e biotita $(2 \%)$ aparecem como minerais secundários retrógrados. Merece destaque o fato de a granada encontrar-se em processo de destruição, já que exibe coroas reacionárias com textura radial, formada por fina matriz de plagioclásio e ortopiroxênio neoformados. Quimicamente, são classificadas como rochas basálticas ( $\mathrm{SiO}, 48-54 \%)$, de filiação toleítica; alguns níveis apresentam teores elevados em ferro e titânio, comparáveis com os metabasaltos ricos nesses elementos, que ocorrem na região de Maraú, aos quais estão relacionados ocorrências de manganês (Barbosa 1986).

Complexo Ibicaraí-Buerarema Ocupa partes dos setores ocidental, sul e centro-leste da área estudada, sendo composto predominantemente de granulitos intermediários e félsicos e, subordinadamente, de granulitos máficos (Fig. 2).

Granulitos intermediários e félsicos As rochas são em geral homogêneas, mas com proeminente foliação vertical (S3) relacionada à terceira fase de deformação (D3). Possuem geralmente discreto bandamento, embora na porção oeste apresentem expressivo bandamento gnáissico, traduzido por alternâncias centimétricas a métricas de níveis félsicos e intermediários-félsicos, provavelmente produto da intensa transposição ligada à terceira fase de deformação. Esses granulitos são de coloração predominantemente cinza-escuro, com granulação variável de fina a média, e destaque para esporádicos níveis grossos contendo quartzo e plagioclásios estirados.

Os estudos petrográficos desses litótipos definiram textura granoblástica eqüigranular a ineqüigranular, com grãos vez por outra poligonizados. Os granulitos intermediários apresentam paragênese tipomorfa, formada essencialmente de plagioclásio (55\%) (An 20-40), quartzo (25\%), ortopiroxênio $(7 \%)$ e clinopiroxênio $(8 \%)$. Feldspato potássico pertítico $(1 \%)$ e hornblenda primária $(1 \%)$ ocorrem subordinadamente. Hornblenda e biotita secundárias $(3 \%)$ também, às vezes, aparecem como resultado de processos retrometamórficos gerados por transformações e/ou reações entre os componentes da paragênese metamórfica primária. Os granulitos félsicos têm mineralogia desprovida de minerais ferromagnesianos, sendo ricos em plagioclásio $(70 \%)$ (An 20-30) e quartzo $(30 \%)$.

Granulitos máficos Constituem corpos isolados inclusos nos granulitos intermediários. Têm forma lenticular e apre- 
sentam-se fortemente estirados pela deformação regional (D3) e dispostos paralelamente à orientação preferencial NS. Mostram-se com coloração dominantemente cinza-escura e apresentam granulação de fina a média, embora vez por outra exibam granulação grossa.

A paragênese metamórfíca primária é composta de plagioclásio (50\%) (An 32) + clinopiroxênio $(25 \%)$ + hornblenda $(20 \%)$. Fenômenos retrometamórficos ocasionaram o aparecimento de biotita $(1 \%)$, hornblenda $(2 \%)$ e granada $(2 \%)$, que ocorrem sob a forma de traços. A granada é proveniente da reação entre plagioclásio e ortopiroxênio, este último ficando preservado dentro da fase mineral neoformada. Vale destacar que, em partes onde a textura da rocha é grossa, é possível admitir que cristais maiores de plagioclásio + ortopiroxênio + clinopiroxênio sejam plutônicos, sobretudo quando, ao lado destas fases minerais, outra associação de cristais menores de plagioclásio+ ortopiroxênio+clinopiroxênio está presente. Outra evidência, talvez plutônica, notada nessas partes grossas da rocha, é a presença de bandas centimétricas $(20$ a $30 \mathrm{~cm})$ de plagioclásio + ortopiroxênio + clinopiroxênio, alternadas com bandas também centimétricas de plagioclásio +quartzo, admitidas como formadas provavelmente por meio de processos de diferenciação magmática primária de corpo ígneo. Em lâmina delgada, possível textura de cúmulo é assinalada pela disposição do plagioclásio, que funcionou como mineral de cúmulo; o piroxênio mineral pós-cúmulo.

Apesar das poucas evidências da natureza original plutônica na grande maioria dessas rochas, elas não são muito notadas por causa da alta intensidade das deformações e recristalizações a que foram submetidas. Dessa forma, por um lado, é possível generalizar e admitir que todas essas evidências plutônicas foram destruídas pelas deformações. Por outro lado, pode-se também supor que boa parte dessas rochas é de origem vulcânica, tendo sido deformadas e recristalizadas na fácies granulito, já que a maioria apresenta textura média a fina e somente com uma paragênese tipomorfa da fácies granulito. Assim, é considerado que pode ter predominado a primeira possibilidade, a segunda, ou ambas associadas, sendo difícil priorizar qualquer uma delas. Porém, tanto a mineralogia como a petroquímica (Barbosa 1991) têm mostrado que os granulitos máficos, intermediários e félsicos do Complexo Ibicaraí-Buerarema fazem parte de suíte cálcio-alcalina de baixo potássio. Os granulitos máficos podem ter sido gabronoritos e/ou basaltos, os granulitos intermediários, dioritostonalitos-enderbitos e/ou andesitos-dacitos, e os granulitos félsicos, trondhjemitos e/ou riolitos.

Granitóides Água Sumida, Rio Paraíso e São Geraldo Os granitóides que ocorrem na área têm maior dimensão na direção meridiana, sendo separados pelas feições estruturais, petrográfícas e litogeoquímicas. Foram denominados de Água Sumida, Rio Paraíso e São Geraldo e, pela morfologia parece que foram intrusivos nos granulitos do Complexo IbicaraíBuerarema.

No granitóide Água Sumida (Fig. 2) foram identificados monzodioritos, monzonitos e sienitos, todos reequilibrados na fácies granulito. Em princípio, constituem suíte plutônica relativamente bem diferenciada. Os monzonitos e quartzo monzonitos, que são as rochas predominantes na suíte, são homogêneos, de cor cinza-esverdeado, textura média a grossa, sendo visível a foliação vertical da terceira fase (S3), associada a movimentos transcorrentes. Em lâmina delgada, essas rochas apresentam textura granoblástica, ineqüigranular, e duas paragêneses: primeira, provavelmente plutônica, formada de cristais maiores de mesopertita $(60 \%)$, ortopiroxênio $(15 \%)$, clinopiroxênio (12\%), plagioclásio antipertítico do tipo andesina $(7 \%)$, quartzo $(4 \%)$, hornblenda $(1 \%)$ e biotita (1\%); a segunda, possivelmente metamórfíca, formada de cristais menores, orientados paralelamente à foliação constituída de plagioclásio, ortopiroxênio e clinopiroxênio. Ao norte da área estudada, Barbosa (1991) identificou rochas semelhantes, nas quais foram calculadas temperaturas superiores a $900^{\circ} \mathrm{C}$ nos cristais maiores de ortopiroxênio - clinopiroxênio da primeira paragênese, e temperaturas inferiores a $850^{\circ} \mathrm{C}$ nos cristais menores, desses mesmos minerais, pertencentes à segunda paragênese. As temperaturas da primeira paragênese estão sendo consideradas como plutônicas, parcialmente reequilibradas na fácies granulito e, as da segunda, como metamórficas (Barbosa 1991).

O granitóide Rio Paraíso (Fig. 2) situa-se na parte norte e sudoeste da área e constitui-se quase exclusivamente de monzonitos. Os monzonitos apresentam grande uniformidade textural, interrompida apenas por delgadas bandas enriquecidas em minerais máficos, as quais são paralelas ao plano de foliação S3 - única observada nessas rochas. Apresentam textura dominantemente granoblástica. com antigos fenocristais de quartzo $(18 \%)$, plagioclásio antipertítico $(45 \%)$, piroxênios $(18 \%)$, feldspato potássico $(5 \%)$, hornblenda $(3 \%)$ e biotita $(2 \%)$. Estes estão estirados e imersos numa matriz de plagioclásio (10\%) (An 30-50) e quartzo (20\%). Os cristais grossos, estirados, podem ser considerados como plutônicos ou como produto do primeiro metamorfismo granulítico. Os cristais menores da matriz podem ser relacionados à primeira fase metamórfíca, caso as mais grossas sejam plutônicas, ou à segunda fase metamórfíca, se os cristais mais grossos forem da primeira fase de metamorfismo.

O Granitóide São Geraldo localiza-se ao sul da área (Fig. 2); insere rochas ortognáissicas de textura granoblástica, de composição granítica dominante e com diferenciação local para monzonito. É constituído, principalmente, por quartzo $(40 \%)$, microclínio $(33 \%)$ e plagioclásio $(27 \%)$ do tipo andesina.

Para a petroquímica, todos estes granitóides têm caráter subalcalino, com afinidades shoshoníticas. Os termos mais básicos da "suíte" Água Sumida apresentam similaridades químicas com os metagabros shoshoníticos descritos por Barbosa (1 986) e Barbosa \& Fonteilles( 1989), devendo fazer parte do conjunto de rochas shoshoníticas/alcalinas descritas por Barbosa $(1990,1991)$.

Sobre a geocronologia, datações radiométricas pelo método $\mathrm{Rb}$-Sr acusaram idade de $2.325+10 \mathrm{Ma}(\mathrm{Ri}=0,7018$; MSWD $=5,42414$ ) para rochas do corpo de Água Sumida. Este valor praticamente coincide com aquele determinado por Moorbath et al. (no prelo, apud Barbosa 1990), para rochas semelhantes situadas ao norte da região estudada, que foi de $2.400+130$ Ma pelo método Sm-Nd, idade modelo.

Complexo Rio Japu As rochas que compõem este complexo ocupam uma faixa de terreno situada a sudoeste da cidade de Ilhéus. Elas estão estruturadas na direção NE-SW, e sofreram as mesmas deformações das rochas adjacentes, destacando-se as foliações/bandamentos S3 das deformações D3. Litologicamente, o Complexo Rio Japu está representado por biotita e hornblenda gnaisses; biotita granodiorito-gnaisses ocorre sob a forma de corpos individualizados. Essas rochas são comparáveis àquelas do Complexo Ibicaraí-Buerarema, pois possuem igualmente o caráter intermediário e félsico. Entretanto, estas últimas foram reequilibradas na fácies granulito. As rochas do Complexo Rio Japu são da fácies anfíbolito cristalizadas em níveis crustais menos profundos, provavelmente acima da isógrada do "hiperstênio".

Os hornblenda e biotita gnaisses são rochas em geral de coloração cinza-claro, granulação fina a média, com bandamento refletido pela alternância de níveis $(5-10 \mathrm{~cm})$ constituídos por minerais ferromagnesianos, quartzo e feldspatos, e com níveis contendo exclusivamente quartzo e feldspatos. As paragêneses encontradas nesses gnaisses, compostas de plagioclásio (andesina) $(50 \%)+$ quartzo $(25 \%)+$ hornblenda $(13 \%)+$ biotita $(10 \%)+$ microclínio $(2 \%)+$ granada ou plagioclásio (andesina) $(50 \%)+$ quartzo $(30 \%)+$ biotita $(13 \%)+$ hornblenda $(7 \%)+$ granada, são indicativas de condições metamórficas de médio grau da fácies anfíbolito. 
A ausência de restos de ortopiroxênio, bem como de qualquer remanescente de mesopertita e antipertita, permite concluir que estas rochas jamais foram submetidas às condições da fácies granulito. O retrometamorfismo nesses gnaisses manifesta-se em corredores de maior deformação, onde biotita, gerada a partir da hornblenda, faz-se presente em elevado percentual.

Os biotita granito gnaisses e biotita granodiorito gnaisses diferem dos anteriores porque aqueles são mais ricos em plagioclásio e estes em feldspato potássico. Essas rochas com biotita são de cor dominantemente cinza-claro, granulação fina a média, por vezes grossa, e bandadas. Exibem localmente textura augen e incluem, às vezes, xenólitos de anfibolitos ( $1 \mathrm{~m}$ de comprimento e $30 \mathrm{~cm}$ de largura) distribuídos dispersamente; é notada foliação interna, realçada por intercalações de finíssimas faixas ricas em plagioclásio com outras fartas em hornblenda. A paragênese principal é composta de quartzo $(35 \%)+$ microclínio $(30 \%)+$ plagioclásio (oligoclásioandesina) $(23 \%)+$ biotita $(12 \%) \pm$ hornblenda no caso do biotita granito gnaisses, e plagioclásio (andesina) $(45 \%)+$ quartzo $(30 \%)+$ microclínio $(18 \%)+$ biotita $(7 \%)$ no caso dos biotita granodiorito gnaisses. Essas paragêneses indicam, de forma semelhante aos hornblenda e biotita gnaisses anteriores, que essas rochas também foram recristalizadas em ambiente da fácies anfibolito.

METAMORFISMO A tectônica e o metamorfismo que atuaram sobre as rochas da área produziram recristalizações identificadas pelas texturas cristaloblásticas, poligonais e às vezes reacionais, que permitiram identificar fácies metamórficas de alto grau, progressivas e regressivas.

Fácies anfibolito progressiva As paragêneses metam órficas encontradas nas rochas do Complexo Rio Japu indicam que elas jamais alcançaram o grau granulito. Foram formadas, portanto, em nível crustal superior daquele correspondente às rochas granulíticas da região, apresentando características químicas semelhantes a estas, embora mostrem paragêneses da fácies anfibolito (Fig. 2). Os gnaisses que predominam no Complexo Rio Japu possuem textura em geral cristaloblástica, com paragêneses predominantes dos $\mathbf{1}$. hornblenda + biotita + plagioclásio + quartzo; 2. biotita + plagioclásio + microclínio + quartzo e 3. granada + biotita + plagioclásio + quartzo, esta última mais rara. Essas associações mineralógicas, juntamente com a ausência de ortopiroxênio, mesopertita - microclínio pertítico ou plagioclásio antipertítico, indicam que essas rochas devem ter sido formadas acima da isógrada do ortopiroxênio.

Fácies granulito progressiva Em alguns granulitos básicos da região, ricos em hornblenda e desprovidos de quartzo, foram identificadas associações metaestáveis que indicam progressão das condições metamórficas em direção à fácies granulito. Por exemplo, $\mathrm{Hb}+$ Plag $\Leftrightarrow=\mathrm{Opx}+\mathrm{Opaco}, \mathrm{Hb}+\mathrm{Plag}$ $\Leftrightarrow$ Gt + Opaco, $\mathrm{Hb}+$ Plag + Qzo $\Leftrightarrow$ Cpx e $\mathrm{Hb}+$ Qzo $\Leftrightarrow$ Opx $+\mathrm{Cpx}+$ Plag, todas com perda de $\mathrm{H}_{2} \mathrm{O}$, são reações que correspondem à desidratação das rochas na fácies granulito pelo aumento progressivo da temperatura e pressão do metamorfismo. A coexistência de hornblenda rica em titânio mais piroxênio com pleocroísmo verde acastanhado, em equilíbrio nessas rochas, indica que todo o quartzo originalmente existente foi consumido pelas reações anteriores para formar piroxênios mais plagioclásio com expulsão de fluido. As paragêneses metamórficas com contatos poligonais compostas de plagioclásio + quartzo + piroxênio encontradas nos granulitos intermediários e ortopiroxênio + clinopiroxênio + plagioclásio + granada encontrada em certos granulitos básicos da região mostram que elas são tipomorfas, formadas no pico do metamorfismo granulítico.

Rochas com textura grossa, como por exemplo os granitóides denominados Água Sumida, às vezes mostram duas paragêneses compostas de ortopiroxênio-clinopiroxênio. $\mathrm{Na}$ dupla de piroxênios mais grossos, observam-se lamelas de exsolução de opacos e lamelas de clinopiroxênio em ortopiroxênio. Naquela formada por cristais menores de piroxênios, esses fenômenos são inexistentes. Em rochas semelhantes, que ocorrem ao norte da área estudada, Barbosa (1991) determinou temperaturas superiores a $900^{\circ} \mathrm{C}$ nos pares de piroxênios grossos e $830^{\circ} \mathrm{C}$ nos pares de ortopiroxênioclinopiroxênio mais finos. As primeiras temperaturas foram admitidas como plutônicas, parcialmente reequilibradas pelo metamorfismo granulítico, o qual produziu cristais menores de piroxênios, justamente aqueles onde são registradas as temperaturas de $830^{\circ} \mathrm{C}$.

Fácies granulito regressiva Nas rochas da região, foram identificadas reações metamórficas que desequilibraram parcialmente as paragêneses tipomorfas. Parece que estas reações aconteceram ainda em ambiente da fácies granulito, em condições físicas inferiores à do pico metamórfico.

Reações estáticas do tipo Cpx $+\mathrm{Gt} \Leftrightarrow \mathrm{Opx}+\mathrm{Plag}$, sugeridas pela presença de coroas reacionais de ortopiroxênio mais plagioclásio, entre grãos de clinopiroxênio mais granada e encontradas nos granulitos básicos com granada do Complexo São José, são registradas como ligadas a rebaixamento da pressão em ambiente de alto grau metamórfíco (De Waard 1965), Na fácies granulito, é observada a existência de simplectitos de granada mais quartzo, gerados a partir da reação estática Opaco + Plag o Gt + Qz (Mc Lelland \& Whitney 1980), encontradas em granulitos básicos. Produtos de ambos os tipos de reações são encontrados ao norte da região estudada, em granulitos básicos com granada de filiação toleítica, tendo sido interpretados como gerados a partir do abaixamento da pressão e da temperatura, respectivamente, função do levantamento de blocos crustais ligado à deformação transcorrente dúctil, que atingiu fortemente os terrenos costeiros atlânticos (Barbosa 1990).

Fácies anfibolito regressiva Transformações metamórficas regressivas, as quais transformam parcialmente ou totalmente paragêneses da fácies granulito em paragêneses da fácies anfibolito, são identificadas na região. As reações metamórficas indicativas de transformações mineralógicas podem ter ocorrido estaticamente ou podem ter sido dinâmicas, síncronas às deformações tectônicas tardias que atuaram na área. Estas deformações dinâmicas tardias, embora mostrem em geral seus planos penetrativos verticais, ligados à deformação D3 de cisalhamento dúctil, ocorreram em ambiente da fácies anfibolito. Isto é verificado sobretudo pelas reações do tipo Opx $+\mathrm{Cpx}+\mathrm{Plag}+\mathrm{H}_{2} \mathrm{O}<=>\mathrm{Hb}+\mathrm{Qz}$ e Opx $+\mathrm{K}_{2} \mathrm{O}+\mathrm{H}_{2} \mathrm{O} \Leftrightarrow>\mathrm{Bi}+\mathrm{Qz}$ também identificadas por Lima et ai. (1982) e Barbosa (1986). As reações demonstram que durante o cisalhamento dúctil houve elevação de blocos de granulitos para porções mais superficiais da crosta e introdução de fluídos ricos em água através das zonas de cisalhamento. Microfraturas preenchidas por anfibólio e biotita também corroboram as evidências encontradas de penetração de fluido na rocha.

Fácies xisto-verde regressiva Sericita, clorita, carbonato e enstantita alterada são fases minerais secundárias, de alteração, formadas em nível crustal mais superficial que os anteriores, equivalente àquele compatível com a fácies xistoverde do metamorfismo regional. Em rochas miloníticas, estes minerais estão estirados e dispostos discordantemente em relação à foliação/bandamento da fácies granulito. Em rochas nas quais são evidentes essas fases minerais retrógradas, em lâmina delgada, é verificada a rotação e deslocamento dos grãos ao longo de zonas de cisalhamento. Em zonas localizadas e situadas sobretudo em corredores de transposição do Complexo Rio Japu, ocorre a paragênese típica da fácies xisto-verde, composta por carbonato + epídoto + albita 
+ moscovita + microclínio + quartzo, encontrada sobretudo em biotita granodioritos gnáissicos, provenientes dos efeitos retrometamórficos sobre a paragênese mineral das fácies granulito e anfibolito. Nessas rochas, em alguns casos, é notada ainda a presença de muscovita, formada a partir de biotita, com a mesma orientação desta última, sugerindo processos de cisalhamento paralelos à foliação regional em direção N $10-15^{\circ} \mathrm{E}$

Termobarometria Uma das utilidades de determinações quantitativas de constituintes químicos contidos nos minerais de rochas metamórficas, é a possibilidade de estimar as condições físicas de temperatura e pressão que presidiram o metamorfismo. Para obter as temperaturas e pressões metamórficas, foram realizadas em amostras de granulitos da região, análises químicas em ortopiroxênios, clinopiroxênios, plagioclásios e granadas. Entre as rochas que tiveram essas fases minerais analisadas em microssonda eletrônica, destacam-se os granulitos básicos com granada do Complexo São José e os granulitos básicos também com granada do Complexo Ibicaraí-Buerarema.

As fases minerais presentes nessas rochas estão em geral em equilíbrio. Entretanto, em alguns casos, existem associações metamórficas metaestáveis, que indicam queda das pressões e temperaturas. Assim, com análises químicas nos centros e nas bordas dos minerais das paragêneses metamórficas primárias e naqueles que fazem parte das coroas reacionais, foi possível determinar faixas de variação de T e P do metamorfismo.

Os dados obtidos com o geotermômetro de Wells (1977) variaram de $702^{\circ} \mathrm{C}$ a $864^{\circ} \mathrm{C}$, sendo maior a incidência de valores da ordem de $850^{\circ} \mathrm{C}$ (Tab. 1). Como esses últimos foram obtidos em rochas nas quais não há sinais evidentes de desequilíbrio, foram admitidos como correspondentes ao pico do metamorfismo. Inversamente, os valores abaixo de $800^{\circ} \mathrm{C}$, encontrados em rochas parcialmente desestabilizadas, foram considerados como retrógrados, pertencentes às fácies granul ito e anfibolito regressivas (Barbosa 1986).

Os valores obtidos para as pressões de cristalização, pelo método de Wells (1979), o qual parece fornecer resultados mais compatíveis para as rochas da região (Barbosa \& Fonteilles 1986, Barbosa 1988), variam entre 4,66 a 7,24 kbar (Tab. 1). Entretanto, houve maior concentração de valores em torno de $6 \mathrm{kbar}$, cifra considerada como a pressão predominante na geração dos terrenos metamórficos de alto grau da área em estudo.

A figura 4 exibe comparação entre os valores de temperatura e pressão conseguidos para as rochas da região de Itabuna, aqueles do Domínio da Costa Atlântica (Barbosa 1986,1990,1991), edeoutrosterrenosgranulíticosarqueanos/ proterozóicos inferior encontrados no mundo. Os pontos à direita do diagrama são considerados como valores de $\mathrm{T}$ e $\mathrm{P}$, próximos ao pico do metamorfismo, enquanto aqueles situados à esquerda são vistos como valores regressivos, pois, efetivamente, foram obtidos em rochas onde eram evidentes sinais de desequilíbrio paragenético.

DISCUSSÕES E CONCLUSÕES As rochas metamórficas de alto grau encontradas na região de Itabuna, são semelhantes, na composição, àquelas encontradas ao norte e consideradas por Barbosa (1986) como parte do Domínio da Costa Atlântica, o qual foi posteriormente definido por Barbosa (1990), como representante de provável arco ou de conjunto de arcos de ilhas, de idade arqueana/proterozóica, profundamente erodido. Estes arcos de ilhas poderiam ter sido originados da fusão com produção de magma cálcio-alcalino toleítico, e shoshonítico de suposta placa oceânica, situada a leste do Domínio da Costa Atlântica e com vergência para oeste. Com isso, é possível considerar: 1. os granulitos básicos e os granulitos básicos com granada do Complexo São José (Fig. 2) como correlacionáveis aos granulitos máfícos com granada (Barbosa 1990,1991), cujos protólitos foram basaltos
Tabela 1 - Valores de temperaturas e pressões da área estudada segundo os métodos de Wells (1977 e 1979) Table I-Temperature and pressure values of the studied area according to the methods of Wells (1977 and 1979)

\begin{tabular}{|c|c|c|c|c|c|}
\hline ORTOPtROXËNI & CZAMOPIROXE்NFO & PLAGTOCLASIB & GRANADA & $\begin{array}{l}\text { TERFERATURA } \\
\text { GHAS C) }\end{array}$ & 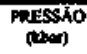 \\
\hline 107 & 110 & 109 & 90 & 843 & 5,70 \\
\hline 97 & I to & 109 & $\$ 9$ & 840 & $5,6]$ \\
\hline 107 & III & 98 & 99 & 364 & 5,72 \\
\hline 107 & ItI & 104 & 100 & 854 & 7,24 \\
\hline 97 & 110 & 104 & 106 & $\$ 40$ & 5,35 \\
\hline 107 & 110 & 109 & 106 & $\mathbf{4 3}$ & 5,75 \\
\hline 97 & III & 98 & 101 & $\$ 1$ & 7,20 \\
\hline 377 & 376 & 375 & 373 & 702 & 4,69 \\
\hline 377 & 272 & 375 & 373 & 230 & 4,66 \\
\hline 113 & 114 & 117 & $\$ 12$ & $\$ 52$ & 6.26 \\
\hline
\end{tabular}

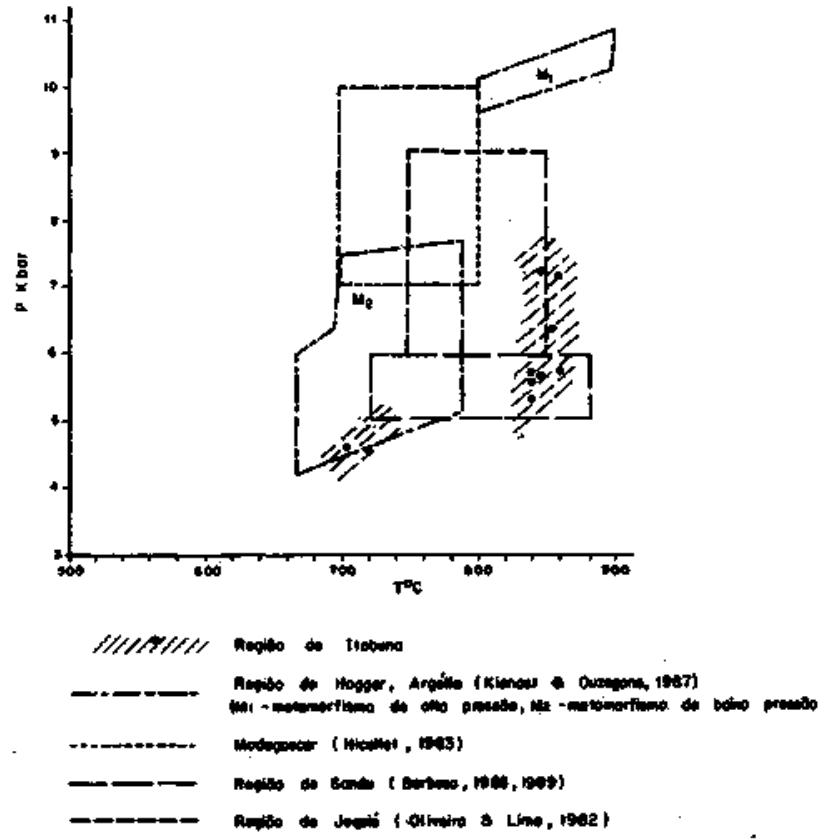

Figura 4 - Comparação dos valores de temperatura e pressão da região pesquisada, do Domínio da Costa Atlântica e de outras regiões granulíticas do mundo

Figure4-Graphicalcomparisonofthe temperature and pressurevaluesofthe studied area, of the Atlantic Coast Domain and of other granul itic regions in the world

e/ou gabros toleíticos de arcos vulcânicos; 2. os granulitos intermediários do Complexo São José e os granulitos intermediários e félsicos do Complexo Ibicaraí-Buerarema (Fig. 2), como a continuação sul dos granulitos intermediários e félsicos de Barbosa (1990), tendo como rochas originais prémetamórficas, uma seqüência magmática cálcio-alcalina, bem diferenciada formada de andesitos basáíticos e/ou dioritos, andesitos e/ou quartzo dioritos, dacitos e/ou tonalitosenderbitos e riolitos e/ou trondhjemitos (Barbosa 1991); e, finalmente, 3. os granitoides Água Sumida, Rio Paraíso e São Geraldo (Fig. 2), como correspondentes meridionais das 
rochas descritas por Barbosa (1986, 1989, 1990 e 1991), no Domínio da Costa Atlântica, como provenientes de um magma shoshonítico-alcalino. As rochas do Complexo Ilhéus (Figs. 2 e 3), onde foram encontrados granulitos ricos em hornblenda e rochas com escapolita, podem representar evidências de basaltos e/ou gabros de fundo oceânico e sedimentos margosos, salinos (evaporitos?), respectivamente. Isto pode indicar, na parte leste da área de Itabuna, a presença de vestígios da suposta placa oceânica subductada (Barbosa 1990,1991) e da margem externa do arco de ilha.

As rochas do Complexo Rio Japu aparentemente são as correspondentes metamorfizadas na fácies anfibolito progressiva, das rochas granulíticas do Complexo IbicaraíBuerarema. Possuem posição metamórfica e geotectônica semelhante àquelas encontradas na denominada Banda de Ipiaú (Barbosa 1986) ou Domínio de Ipiaú (Barbosa 1990, Barbosa \& Fonteilles 1991), situadas a noroeste da região de Itabuna.

Os valores de pressão e temperatura obtidos neste trabalho, para o metamorfísmo de alto grau da região, de uma maneira geral, situaram-se em torno de 6 kbar e $850^{\circ} \mathrm{C}$. São dados que coincidem com aqueles encontrados por Barbosa (1990) no Domínio da Costa Atlântica, permitindo classificar o metamorfísmo granulítico como do tipo alta temperatura-média pressão. Entretanto, nesta região e nos seus arredores oeste, são verificadas evidências de pressão, aparentemente isoladas, mais elevada que 6 kbar. Como exemplos, são citadas as paragêneses ortopiroxênio+granada encontradas nos granulitos básicos com granada do Complexo São José, a 7,5 kbar, e as paragêneses com safirina+quartzo, encontradas nos sedimentos metaluminosos-magnesianos, migmatizados-granulitizados, situados próximos à cidade de Almadina. A última paragênese indica pressões superiores a 9 kbar e temperaturas metamórficas extremas, em torno de $1.000^{\circ} \mathrm{C}$, desde que a safírina analisada na microssonda demonstre ser pobre em ferro (Seixas, dissertação de mestrado em preparação na UFBA). Os altos valores, discrepaníes com a média regional, podem ser explicados, seja considerando que os métodos termobarométricos, termodinâmicos ou experimentais, não são compatíveis quando aplicados em rochas com química diferente (Barbosa \& Fonteilles 1986) seja admitindo que estão associados a blocos tectônicos isolados e restritos, formados em níveis crustais mais profundos e que foram trazidos tectonicamente para partes mais superficiais, quando da incidência dos processos de colisão-obducção-duplicação da crosta (arqueana/proterozóica local), segundo o modelo de Barbosa (1990). Esta última possibilidade parece ser a mais viável.

As deformações da área em foco são também reflexo desses processos de colisão-obducção-duplicação dessa parte da crosta. A existência de pares de ortopiroxênio-clinopiroxênio em equilíbrio e com contatos retos, situadas tanto em bandas suborizontais de granulitos, proveniente das deformações D1 e D2, como em bandas subverticais, oriundas da deformação D3, com transcorrências NNE associadas, indicam que o pico do metamorfísmo regional foi provavelmente alcançado após a paralisação dessas deformações dúcteis. Este fato é também corroborado pela presença de veios ou bolsões de mobilizados com ortopiroxênio, não deformados, secantes ou paralelos ao bandamento, além da existência de granadas euedrais e texturas poligonais com ortopiroxênio-plagioclásio em equilíbrio (Barbosa 1986). Deformações pós pico metamórfíco parece que ocorreram aproveitando as zonas de transposiçãotranscorrência NNE, mas, quando este segmento crustal encontrava-se em partes mais superficiais da crosta, em ambiente da fácies anfíbolito. Esta interpretação pode ser feita por causa da formação de hornblenda e biotita, estiradas, retrógradas, originadas a partir de piroxênio, e concentradas em zonas paralelas àquelas de direção NNE. Nesses corredores retrógrados, as paragêneses secundárias foram recristalizadas dinamicamente. Entre eles, entretanto, paragêneses de mais baixo grau formaram-se em condições estáticas. Nesses locais, como as deformações retrógradas foram praticamente inexistentes, são verificadas bons exemplos de coroas reacionais.

Agradecimentos Os autores agradecem ao geólogo João Pereira das Neves, pela revisão do texto e sobretudo ao Professor Shiguemi Fujimori, pela leitura, críticas e sugestões apresentadas ao manuscrito. Também são gratos à Companhia de Pesquisa de Recursos Minerais (CPRM), ao Conselho Nacional de Desenvolvimento Científico e Tecnológico (CNPq) e à Superintendência de Geologia e Recursos Minerais da Secretaria da Indústria Comércio e Turismo do Estado da Bahia (SICT), que direta ou indiretamente permitiram a realização dessas pesquisas.

\section{REFERÊNCIAS BIBLIOGRÁFICAS}

ARCANJO, J.B.A. (org.) 1991. Itabuna, folha SD. 24-Y-B-VI; Estado da Bahia. Texto explicativo. Brasília, DNPM/PLGB. (No prelo).

BARBOSA, J.S.F. 1986. Constitution lithologique et metamorphique de Ia region granulitique du sud de Bahia-Brésil. Bris. 401 p. (Tese de Doutoramento, Université Pierre et Marie Curie, Paris VI).

BARBOSA, J.S.F. 1988. Principais geobarômetros utilizados em granulitos: análise dos resultados de um exemplo do sul da Bahia-Brasil. Rev. Bras. Geoc., 18(2): 162-169.

BARBOSA, J.S.F. 1989. Química mineral utilizadana identificacão das fácies metamórficas da região granulítica do sul da Bahia, Brasil. Rev. Bras. Geoc.,19(3):350-366.

BARBOSA, J.S.F. 1990. The granulites of the Jequié Complex and Atlantic coast mobile belt, Southern Bahia - An expression of Archean/Early Proterozoic plate convergence. In: VIELZEUF, D. \& VIDAL, Ph. eds. GranulifesandCrustal Evolution.K|uv/er Academic Publishers, p. 195221

BARBOSA, J.S.F. 1991. Projeto Geologia e Metalogenia do Domínio da Costa Atlântica da Região Granulítica do Sul da Bahia-Brasil. Convênio SME/SGM/UFBA/PPPG. (Relatório Inédito).

BARBOSA, J.S.F. \& FONTEILLES, M. 1986. Examen critique dês résultats foumis par certains barpmetres courament utilises en terrains granulitiques. Exemples dês granulitiques de Bahia (Brésil et du Massif de 1'Agly, France). Bull. Mineral., 109:359-376.

BARBOSA, J.S.F. \& FONTEILLES, M. 1989. Caracterizacão dos protólitos daregião granulítica do sul daBahia-Brasil./tev. Brás. Geoc., 19(1):3-16

BARBOSA, J.S.F. \& FONTEILLES, M. 1991. O metamorfísmo da região granulítica do sul da Bahia-Brasil. Rev. Bras. Geoc. ,21(4): 329-341.

CORDANI, U.G. 1973. Evolução geomorfológica precambriana da faixa costeira do Brasil entre Salvador e Vitória. São Paulo. 98 p. (Tese de Livre Docência, IG/USP).
CORDANI, U.G. \& IYER, S.S. 1979. Geochronological investigation on the Precambrian granulitic terrain of Bahia, Brazil. Precambrian Research, 9(3/4):255-274.

COSTA, L.A.M.\&MASCARENHAS.J.F. 1982. The high-grade metamorphic terrains in the interval Mutuipe-Jequié. Archean-Central Bahia. In: INTERNATIONAL SYMPOSIUM ON ARCHEAN AND EARLY PROTEROZOIC GEOLOGIAC EVOLUTION AND METALLOGENESIS - ISAP. Salvador, 1982. Abstracts and Excursions... Salvador, SME. p. 19-37.

CRUZ, M J. 1989. Le massif du rio Piau: une intrusion de nature gabbroique et anorthositique dans les terrains granulitiques du noyau JequiéBahia-Brésil. Paris. 280 p. (Tese de Doutoramento, Université Pierre et Marie Curie, Paris VI, França).

DELHAL,J.\&DEMAIFFE,D. 1985. U-Pb Archean geochronology ofthe São Francisco craton (Eastern Brazil). Rev. Bras. Geoc., 15(1):55-60.

DEWAARD.D. 1965. The occurence of garnet in the granulite-faciesterrane of the Adirondack highlands. J. Petrol., $6(l): 165-19 l$.

CARRELS, L.M. \& MACKENZIE. F.T. 1971. Evolution of Sedimentary Rocks. New York, Norton. $307 \mathrm{p}$

IYER S.S :CHOUDHURI,A :CORDANI,y.G. 1987. Granulitefacies rocks of Brazil: a review oftheirgeologicsetting, geochronological evolution, petrographic and geochemical characteristics. J. Geol. Soc. India, 29:309326.

IYER, S.S.; CHOUDHURI, A; VASCONCELOS, M.B. A.; CORDANI, U.G. 1984. Radioative element distribution in the Archean granul ite terrane of Jequié, Bahia, Brazil. Contrib. Mineral. Petrol., 85:95-101.

KIENAST, .R. \& OUZEGANE, K. 1987. Polymetamorphic AI-Mg rich granulites with orthopyroxene-sillimanite and saphirine paragêneses in archean rocks from Hoggar, Algeria. Geol. J., 22:57-79.

LIMA, M.I.C.; FONSECA, E.G.; OLIVERA, E.P. 1981. Geologia. In: PROJETO RAD AMBRASIL.FolhaSD.24 Salvador; geologia, geomorfologia, 
pedologia, vegetação, uso potencial da ter rã. Rio de Janeiro, p. 25-192. (Levantamento de Recursos Naturais 24).

LIMA, R C.\& ROCHA, A.J.D · COSTA, JV.G.; SILVA, JF. 1982. Projeto turfanafaixacosteiraBahia-Sergipe. Relatório Integrado. 2 v. Salvador, CPRM. (Convênio DNPM/CPRM)

MARTINS, A.A.M.\& SANTOS, R.A.(orgs.) 1991. Ibicaraí,folhaSD.24-Y-B-V; Estado da Bahia. Texto Explicativo. Brasília, DNPM/PLGB. (No prelo).

MASCARENHAS,J.F. 1979. Estruturas do tipo Greenstone Belt no leste da Bahia. In: INDA, H.A.V. ed. Geologia e Recursos Minerais do Estado da Bahia; Textos Básicos. Salvador, SME/CPM. 2:25-53.

McLELLAND,J.M.\& WHITNEY, P.R. 1980. A generalized garnet-forming reaction for metaigneous rocks in the Adirondacks. Contrib. Mineral. Petrol., 72:111-122.

MIRANDA, L.L.F.; SOARES, J. V.; CRUZ, M..M.; MORAIS, A.M.V. 1985. Projeto Ubaira-Santa Inès. Salvador, SME/CBPM. v. 1. (Relatório Final)

MIRANDA,L.L.F.;SOARES,J.V.;MORAES, A.M.V. 1982. Geologiada região de Ubaira-Santa Inês. In: CONOR. BRAS. GEOL., 32. Salvador, 1982. Anais... Salvador, SBG. v.1, p. 246-259.

NEVES, B.B.B.; CORDANI, U.G.; TORQUATO, J.R.F. -1980 - Evolução geomorfológica do Precambriano do Estado da Bahia. In: INDA, H. A. V., DUARTE, F.B. eds. Geologia e Recursos Minerais do Estado da Bahia Salvador, SME/CPM, p. 1-101. (Textos Básicos).

NICOLLET,C. 1983. Existencedegranulitesde haute pressionaclinopyroxenegrenat dans les formations precambriennes du Vohibory (SW de Madagascar). C.R. Acad. Sc. Pará, 297:145-148.

OLIVEIRA, E.P.\& LIMA, M.I.C. 1982. Aspectos petroquímicos das rochas granulíticas do Complexo de Jequié e estimativas das condições físicas de metamorfismo. In: CONOR. BRAS. GEOL., 32. Salvador, 1982. Anais... Salvador, SBG v.2, p. 589-602.

OLIVEIRA, E.P.; LIMA; M.I.C.; CARMO, U.F.; WERNICK, E. 1982. The archean granulite terrain from east Brazil. Rev. Bras. Geoc, 12(1 -3):356-368.

RIBEIRO, A.F. 1982. Projeto Manganês de Valença-Gandu. Salvador, CBPM.v. 1.
SAMPAIO, H.A. \& SILVA, R.A. 1988. Mapa metamórfico do Estado da Bahia. Folha Jequié; Esc. 1:250.000. Salvador, SME/SGM. (Publicação Especial).

SEIXAS, S.R.M.; MARINHO, M.M.; MORAES, O.F; AWDZIES, J. 1975. Projeto Bahia II; Geologia das Folhas de Serrinha e Itaberaba. Relatório Final. Salvador, CPRM. (Conv. DNPM/CPRM, 6 v)

SIGHINOLFI,G.P. 1970. Investigation into the deep levels of the continental crust: petrology and chemistry of granul ite facies terrains of Bahia (Brazil). Atti. Soe. Tose. Sci. Nat. Mem. Serie A, 77:327-341.

SIGHINOLFI,G.P. 1971. Investigation into deep crustal levels: fractionating effects andgeochemical trends related to high-grade metamorphism. Geoch. Cosmoch. Acta, 35:1005-1021.

SIGHINOLFI, G.P.; FIGUEIREDO, M.C.M.; FYFE, W.S.; KRONBERG, B.I.;OLIVEIRA,M.A.F. 1981. Geochemistry and petrology of the Jequié Granulitic Complex (Brazil). Contrib. Mineral. Petrol., 78:263-271.

SIGHINOLFI, G.P. \& SAKAI, T. 1977. Uranium and thorium in archean granulite facies terrains of Bahia (Brazil). Geoch. J., II:33-39.

WELLS, P.R.A. 1979. Chemical and thermal evolution of Archean sialic crust Southern West Greenland. J. Petrol., 20:187-226.

WELLS, P.R.A. 1977. Pyroxene thermometry in simple and complex systems. Contrib. Mineral. Petrol., 62:129-139.

WILSON,N. 1987. CombinedSm-Nd,Pb/PbandRb-Sr geochronologyand isotope geochemistry in polymetamorphic Precambrian terrains: examples from Bahia-Brazil and Channel Island, U.K. Inglaterra. 150p. (Dissertação de Mestrado, Oxford University).

WILSON, N.; MOORBATH, S.; TAYLOR, P.N.; BARBOSA, J.S.F. 1988. Archean and early proterozoic crustal evolution in the São Francisco Craton, Bahia, Brazil. Chem. Geol., 70:(1/2): 146.

MANUSCRITO A708

Recebido em 10 de outubro de 1991 Revisão do autor em 24 de marco de 1992 Revisão aceita em 24 de março de 1992 